\title{
Obstetric and perinatal outcome in type 1 diabetes patients with diabetic nephropathy during 1988-2011
}

\author{
Miira M. Klemetti • Hannele Laivuori • \\ Minna Tikkanen • Mika Nuutila • Vilho Hiilesmaa • \\ Kari Teramo
}

Received: 22 August 2014 / Accepted: 16 December 2014 /Published online: 10 January 2015

(C) Springer-Verlag Berlin Heidelberg 2015

\begin{abstract}
Aims/hypothesis Our aim was to analyse possible changes in the glycaemic control, BP, markers of renal function, and obstetric and perinatal outcomes of parturients with diabetic nephropathy during 1988-2011.

Methods The most recent childbirth of 108 consecutive type 1 diabetes patients with diabetic nephropathy and a singleton pregnancy were studied. Two periods, 1988-1999 and 20002011, were compared.

Results The prepregnancy and the first trimester median $\mathrm{HbA}_{1 \mathrm{c}}$ values persisted at high levels $(8.2 \%$ [66 mmol/mol] vs $8.5 \%[69 \mathrm{mmol} / \mathrm{mol}], p=0.16$ and $8.3 \%[67 \mathrm{mmol} / \mathrm{mol}]$ vs $8.4 \%[68 \mathrm{mmol} / \mathrm{mol}], p=0.67$, respectively), but decreased by mid-pregnancy $(6.7 \%$ [50 mmol/mol] vs $6.9 \%$ [52 mmol/ $\mathrm{mol}$ ], $p=0.11$ ). Antihypertensive medication usage increased before pregnancy ( $34 \%$ vs $65 \%, p=0.002)$ and in the second and third trimesters of pregnancy ( $25 \%$ vs $47 \%, p=0.02$, and $36 \%$ vs $60 \%, p=0.01$, respectively). BP exceeded $130 /$ $80 \mathrm{mmHg}$ in $62 \%$ and $61 \%(p=0.87)$ of patients in the first trimester, and in $95 \%$ and $93 \%(p=0.69)$ in the third trimester,
\end{abstract}

M. M. Klemetti $(\bowtie) \cdot$ H. Laivuori $\cdot$ M. Tikkanen $\cdot$ M. Nuutila $\cdot$

V. Hiilesmaa $\cdot \mathrm{K}$. Teramo

Department of Obstetrics and Gynaecology, University of Helsinki and Helsinki University Central Hospital, P.O. Box 140,

Haartmaninkatu 2, 00029 Helsinki, Finland

e-mail: miira.klemetti@helsinki.fi

\section{M. Klemetti}

Department of Obstetrics and Gynaecology, South Karelia Central Hospital, Lappeenranta, Finland

M. M. Klemetti • H. Laivuori

Haartman Institute, Department of Medical Genetics, University of Helsinki, Helsinki, Finland

H. Laivuori

Institute for Molecular Medicine Finland, University of Helsinki, Helsinki, Finland respectively. No changes were observed in the markers of renal function. Pre-eclampsia ( $52 \%$ vs $42 \%, p=0.29)$ and preterm birth rates before 32 and 37 gestational weeks (14\% vs $21 \%, p=0.33$, and $71 \%$ vs $77 \%, p=0.49$, respectively) remained high. The elective and emergency Caesarean section rates were $71 \%$ and $45 \%(p=0.01)$ and $29 \%$ and $48 \%(p=$ $0.05)$, respectively. Neonatal intensive care unit admissions increased from $26 \%$ to $49 \%$ ( $p=0.02$ ).

Conclusions/interpretation Early pregnancy glycaemic control and hypertension management were suboptimal in both time periods. Pre-eclampsia and preterm delivery rates remained high in patients with diabetic nephropathy.

Keywords Antihypertensive medication - Blood pressure Diabetic nephropathy · Glycaemic control - Obstetric outcome - Perinatal outcome Pre-eclampsia - Type 1 diabetes

$\begin{array}{ll}\text { Abbreviations } \\ \text { CS } & \text { Caesarean section } \\ \text { HUCH } & \text { Helsinki University Central Hospital } \\ \text { NICU } & \text { Neonatal intensive care unit } \\ \text { RAS } & \text { Renin-angiotensin system } \\ \text { SGA } & \text { Small-for-gestational age }\end{array}$

\section{Introduction}

Adverse outcomes remain increased in pregnancies of type 1 diabetes patients compared with the general population $[1,2]$. Diabetic nephropathy, which complicates $2.5-5 \%$ of type 1 diabetes pregnancies $[3,4]$, is associated with a particularly high risk of hypertensive disorders of pregnancy, preterm birth, intrauterine growth restriction and perinatal mortality [4-14]. 
Optimisation of glycaemic control and reduction of BP, especially using renin-angiotensin system (RAS) inhibitors, slows the progression and improves the prognosis of diabetic nephropathy [15]. Suboptimal control of BP in early pregnancy is associated with an increased risk of preterm delivery in women with diabetic nephropathy, independent of glycaemic control and duration of diabetes [16]. Based on data from observational studies, the ADA recommends a BP level of $110-129 / 65-79 \mathrm{mmHg}$ in pregnant women with nephropathy [17].

Recent, large reports on pregnancy outcomes of type 1 diabetes patients with diabetic nephropathy are lacking. The objective of this study was to analyse temporal changes in the glycaemic control, BP levels, markers of renal function as well as obstetric and perinatal outcomes of a large population-based cohort of women with diabetic nephropathy during 1988-2011.

\section{Methods}

Subjects We carried out a retrospective analysis of the obstetric records of 145 consecutive pregnancies of type 1 diabetes patients with diabetic nephropathy, who had a live childbirth or a fetal death after completing 22 gestational weeks during 1988-2011 at Helsinki University Central Hospital (HUCH). This hospital is the only centre treating pregnant pregestational diabetes patients in the greater Helsinki area, serving a population of 1.7 million. After selecting only the most recent childbirth of each woman and excluding two twin pregnancies, a total of 108 singleton pregnancies were included in the analyses of maternal and perinatal outcomes. However, the total number of live births and stillbirths (147 infants) was used in the calculation of the perinatal mortality and major malformation rates. Diabetic nephropathy was defined as total protein excretion in urine $\geq 0.3 \mathrm{~g} / 24 \mathrm{~h}$ or dipstickpositive proteinuria $(\geq 1+$ from a midstream clean catch specimen) in each trimester of pregnancy. Parturients with nondiabetic causes of kidney disease were excluded. All patients with diabetic proliferative retinopathy had laser photocoagulation treatment before, during or immediately after pregnancy. An institutional research permit was obtained for the study protocol. The study was carried out in accordance with the Declaration of Helsinki.

Obstetric follow-up Type 1 diabetes patients were referred from primary healthcare centres and local hospitals to the $\mathrm{HUCH}$ as soon as the pregnancy had been diagnosed, usually at $6-10$ gestational weeks. The duration of pregnancy was confirmed by sonography at 11-13 gestational weeks in the majority of pregnancies. During pregnancy, the patients visited the antenatal clinic every $2-4$ weeks and more frequently during the last trimester. Fetal biophysical profile was assessed and weight estimated by ultrasound after 24 gestational weeks at each visit. Maternal BP was measured and urine dipstick analysis was performed at each visit.

Monitoring of renal function Renal function during pregnancy was assessed by total urinary protein excretion in $24 \mathrm{~h}$, serum or plasma creatinine concentration and creatinine clearance. Serum creatinine was analysed using the Jaffe reaction until February 2002, after which an enzymatic method on plasma samples was used. This change in method caused a $10-15 \%$ decrease in creatinine values. The mean decrease in plasma creatinine and creatinine clearance was taken into account and corrected in the statistical analyses when comparing the two time periods. Urine protein concentration was measured by the Biuret method until the early 1990s, and by the benzethonium chloride method thereafter. The highest values of serum or plasma creatinine, total urinary protein excretion and urine dipstick results, the lowest creatinine clearance values in each trimester of pregnancy, and the last values of these markers 12 months before pregnancy were recorded for the purpose of this study. Total urinary protein excretion values $<0.3 \mathrm{~g} / 24 \mathrm{~h}$ were excluded from the analyses if the patient had a positive dipstick result during the same trimester of pregnancy, due to the inaccuracy associated with the $24 \mathrm{~h}$ urine collection [18].

Monitoring of glycaemic status The patients measured their fasting blood glucose and all pre- and postprandial values at least twice per week and took 3-5 daily glucose measurements on other days of the week. $\mathrm{HbA}_{1 \mathrm{c}}$ was assessed every 2-4 weeks by a high-performance liquid chromatography method (Diamat, Bio-Rad Laboratories, Hercules, California, USA). The analysis method of $\mathrm{HbA}_{1 \mathrm{c}}$ did not change during the study period. Four $\mathrm{HbA}_{1 \mathrm{c}}$ values were used for this study: the last value measured within 12 months before pregnancy, the first value measured in the first trimester, one measured in the second trimester between $18+0$ to $22+0$ gestational weeks and the last value recorded before delivery. If two $\mathrm{HbA}_{1 \mathrm{c}}$ values had been measured between $18+0$ and $22+0$ gestational weeks, the average value was used.

Collection of maternal and obstetric data Information on smoking and prepregnancy weight and height were obtained from the maternity care cards where they are recorded as reported by the mother at the first visit to the primary healthcare centre. Data on BP were collected from the maternity care cards and hospital records. The second highest systolic and diastolic BP values in each trimester were recorded. Hypertension during pregnancy according to the conventional criteria was defined as systolic $\mathrm{BP} \geq 140 \mathrm{mmHg}$ and/or diastolic $\mathrm{BP} \geq 90 \mathrm{mmHg}[19,20]$. Hypertension according to the ADA criteria was defined as systolic $\mathrm{BP}>130 \mathrm{mmHg}$ and/ 
or diastolic $\mathrm{BP}>80 \mathrm{mmHg}$ measured repeatedly during pregnancy [17]. Pre-eclampsia in patients with diabetic nephropathy was defined as worsening of hypertension $(\geq 15 \mathrm{mmHg}$ increase in systolic and/or diastolic BP) with a proteinuria level of $\geq 5 \mathrm{~g} / 24 \mathrm{~h}$ after 20 gestational weeks. Data on diabetes duration and complications, antihypertensive medication and delivery modes were collected from hospital records.

Collection of perinatal data Data on gestational age at birth, birthweight, Apgar scores, the lowest blood glucose value of the newborn infant and neonatal intensive care unit (NICU) admission were obtained from patient records. Umbilical artery blood samples were analysed for $\mathrm{pH}$, acid base and haemoglobin concentration using Ciba Corning (Bayer Diagnostics, Fernwald, Germany/Siemens Healthcare Diagnostics, New York, USA), Rapidlab 800 (Bayer/ Siemens) and ABL (Radiometer, Brønshøj, Denmark) pH/ blood gas analysers. Birthweights $>2.0 \mathrm{SD}$ units $(>97.7$ th percentile) were defined as macrosomia and those $<-2.0 \mathrm{SD}$ units $(<2.3$ th percentile) as small-for-gestational age (SGA) using a Finnish standard population standardised for infant's sex and gestational age [21]. Neonatal hypoglycaemia was defined as blood glucose $<2.6 \mathrm{mmol} / \mathrm{l}$ in the early neonatal period.

Statistical methods Continuous variables were analysed with the Mann-Whitney $U$ test or the Student's $t$ test. The $\chi^{2}$ and the Fisher's exact tests were used in the analysis of categorical variables. Bivariate correlations were assessed by either the Pearson's or the Spearman's correlation coefficient, depending on the distribution of the data. Multiple logistic regression analysis was used to study associations of categorical or continuous variables with categorical outcomes. A $p$ value of $<0.05$ was considered statistically significant. The statistical software used was IBM SPSS Statistics 22.0 (www-01.ibm. com/software/analytics/spss/products/statistics/).

\section{Results}

Maternal characteristics The prevalence of diabetic nephropathy in the most recent pregnancies of women with type 1 diabetes was $14.7 \%$ during $1988-1999$ and $6.5 \%$ in 2000 $2011(p<0.001)$. Maternal characteristics of the study population comparing the two 12-year periods, 1988-1999 and 2000-2011, are presented in Table 1. Patients in the latter time period were slightly older. The diabetes duration increased, but the age at diagnosis of diabetes did not differ between the two study periods. No changes were seen concerning parity or BMI. The percentages of smokers and patients with proliferative retinopathy remained high. The prepregnancy and first trimester $\mathrm{HbA}_{1 \mathrm{c}}$ values persisted at high levels, but decreased during both study periods by mid-pregnancy and remained low until the end of pregnancy. The prepregnancy and the first trimester $\mathrm{HbA}_{1 \mathrm{c}}$ levels correlated with the last $\mathrm{HbA}_{1 \mathrm{c}}$ recorded
Table 1 Comparison of maternal characteristics of 108 diabetic nephropathy patients with a singleton delivery at $\mathrm{HUCH}$ during 1988-1999 and 2000-2011
Data are means (SD), medians (range) or frequencies (\%)

The number of subjects is presented in square brackets, if different

${ }^{\text {a }}$ One antepartum stillbirth with an induced vaginal delivery was excluded

\begin{tabular}{|c|c|c|c|}
\hline Maternal characteristic & $1988-1999(n=65)$ & $2000-2011(n=43)$ & $p$ value \\
\hline Age (years) & $29(4.7)$ & $31(5.1)$ & 0.02 \\
\hline Age at diabetes diagnosis (years) & $8(1-21)$ & $8(1-17)$ & 0.69 \\
\hline Duration of diabetes (years) & $19(10-34)$ & $24(12-33)$ & 0.01 \\
\hline Nulliparous & $30(46.2)$ & $26(60.5)$ & 0.15 \\
\hline Prepregnancy BMI $\left(\mathrm{kg} / \mathrm{m}^{2}\right)$ & $23.6(18.8-32.0)[58]$ & $23.4(18.4-38.4)$ & 0.61 \\
\hline Overweight (BMI 25.0-29.9 kg/m²) & $20(34.5)[58]$ & $14(32.6)$ & 0.84 \\
\hline Obese $\left(\mathrm{BMI} \geq 30.0 \mathrm{~kg} / \mathrm{m}^{2}\right)$ & $2(3.4)[58]$ & $1(2.3)$ & 1.00 \\
\hline Smokers & $17(26.2)$ & $12(28.6)$ & 0.78 \\
\hline Proliferative retinopathy & $33(50.8)$ & $28(65.1)$ & 0.14 \\
\hline Prepregnancy $\mathrm{HbA}_{1 \mathrm{c}}(\%)$ & $8.2(5.7-12.5)[36]$ & $8.5(6.1-13.5)[34]$ & 0.16 \\
\hline Prepregnancy $\mathrm{HbA}_{1 \mathrm{c}}(\mathrm{mmol} / \mathrm{mol})$ & $66(39-113)$ & $69(43-124)$ & \\
\hline First $\mathrm{HbA}_{1 \mathrm{c}}$ in first trimester $(\%)$ & $8.3(5.7-11.8)[55]$ & $8.4(5.6-13.7)[41]$ & 0.67 \\
\hline First $\mathrm{HbA}_{1 \mathrm{c}}$ in first trimester $(\mathrm{mmol} / \mathrm{mol})$ & $67(39-106)$ & $68(38-126)$ & \\
\hline Mid-trimester $\mathrm{HbA}_{1 \mathrm{c}}(\%)$ & $6.7(4.7-9.3)[50]$ & $6.9(5.1-9.0)[38]$ & 0.11 \\
\hline Mid-trimester $\mathrm{HbA}_{1 \mathrm{c}}(\mathrm{mmol} / \mathrm{mol})$ & $50(28-78)$ & $52(32-75)$ & \\
\hline Last $\mathrm{HbA}_{1 \mathrm{c}}$ before delivery $(\%)$ & $6.7(4.6-10.0)$ & $6.8(5.3-9.3)$ & 0.67 \\
\hline Last $\mathrm{HbA}_{1 \mathrm{c}}$ before delivery $(\mathrm{mmol} / \mathrm{mol})$ & $50(27-86)$ & $51(34-78)$ & \\
\hline Vaginal delivery $^{\mathrm{a}}$ & $0(0)$ & $3(7.1)[42]$ & 0.06 \\
\hline Elective $\mathrm{CS}^{\mathrm{a}}$ & $46(70.8)$ & $19(45.2)[42]$ & 0.01 \\
\hline Emergency $\mathrm{CS}^{\mathrm{a}}$ & $19(29.2)$ & $20(47.6)[42]$ & 0.05 \\
\hline $\mathrm{CS}(\text { total })^{\mathrm{a}}$ & $65(100.0)$ & $39(92.9)[42]$ & 0.06 \\
\hline
\end{tabular}


before delivery $(r=0.45 p<0.001$ and $r=0.43, p<0.001$, respectively).

One parturient in the first and two in the last time period had at least one blind eye. During 1988-1999, there were two patients with a history of myocardial infarction and one with obliterating arteriosclerosis. Twelve women out of $108 \mathrm{had}$ died by the end of 2013 .

Obstetric outcome The delivery modes are presented in Table 1. Elective Caesarean section (CS) deliveries decreased when the two time periods were compared. The percentage of emergency CS deliveries was high in the last time period, but the change was statistically not significant. The total CS rate remained high at $93 \%$ in the last 12 -year period.

Antihypertensive medications, BP levels and hypertensive disorders The use of RAS inhibitors and other antihypertensive medications before pregnancy increased (Table 2). The use of antihypertensive medications, mainly labetalol and calcium channel blockers, increased in the second and third trimesters of pregnancy. Low-dose aspirin treatment was used during pregnancy in three patients $(4.6 \%)$ in $1988-1999$ and three patients $(7.0 \%)$ in 2000-2011. Hypertension was frequent in both study periods throughout pregnancy (Table 2).

The pre-eclampsia incidence was high in both time periods (Table 2). In patients with pre-eclampsia, the median (range) systolic and diastolic BP levels in the third trimester were 170(137-209) $\mathrm{mmHg}$ and 100(75-112) $\mathrm{mmHg}$, respectively. Their median (range) total protein excretion in urine in the third trimester was $9.6(5.2-22.7) \mathrm{g}$. One case of eclampsia occurred in 1993. Of the pre-eclampsia patients, 12 (23.1\%) delivered before 32 gestational weeks and 44 (84.6\%) before 37 gestational weeks. In logistic regression analysis, preeclampsia was associated with delivery before 37 gestational weeks (OR 3.30, 95\% CI [1.31, 8.34]).
Table 2 Comparison of antihypertensive medication usage, hypertension frequencies and markers of renal function among 108 diabetic nephropathy patients with a singleton delivery at HUCH during 1988-1999 and 2000-2011

Data are medians (range) or frequencies $(\%)$

The number of subjects is presented in square brackets, if different SBP, systolic BP; DBP, diastolic BP

\begin{tabular}{|c|c|c|c|}
\hline Variable & $1988-1999(n=65)$ & $2000-2011(n=43)$ & $p$ value \\
\hline RAS inhibitor used before pregnancy & $16(26.2)[61]$ & $24(55.8)$ & 0.002 \\
\hline \multicolumn{4}{|l|}{ Any antihypertensive medication } \\
\hline Prepregnancy & $21(34.4)[61]$ & $28(65.1)$ & 0.002 \\
\hline 1st trimester & $13(21.3)[61]$ & $14(32.6)$ & 0.20 \\
\hline 2nd trimester & 15 (24.6) [61] & $20(46.5)$ & 0.02 \\
\hline 3rd trimester & $22(36.1)[61]$ & $26(60.5)$ & 0.01 \\
\hline \multicolumn{4}{|c|}{$\mathrm{SBP} \geq 140 \mathrm{mmHg}$ and/or DBP $\geq 90 \mathrm{mmHg}$} \\
\hline 1st trimester & $22(37.9)[58]$ & $20(46.5)$ & 0.39 \\
\hline 2nd trimester & $28(45.2)[62]$ & $26(60.5)$ & 0.12 \\
\hline 3rd trimester & $55(87.3)[63]$ & $35(81.4)$ & 0.40 \\
\hline \multicolumn{4}{|c|}{$\mathrm{SBP}>130 \mathrm{mmHg}$ and/or DBP $>80 \mathrm{mmHg}$} \\
\hline 1st trimester & $36(62.1)[58]$ & $26(60.5)$ & 0.87 \\
\hline 2nd trimester & $37(59.7)[62]$ & $33(76.7)$ & 0.07 \\
\hline 3rd trimester & $60(95.2)[63]$ & $40(93.0)$ & 0.69 \\
\hline Pre-eclampsia & $34(52.3)$ & $18(41.9)$ & 0.29 \\
\hline \multicolumn{4}{|l|}{ Proteinuria (g/24 h) } \\
\hline Prepregnancy & $1.50(0.45-7.70)[13]$ & $0.80(0.34-4.03)[13]$ & 0.42 \\
\hline 1st trimester & $1.55(0.40-11.50)[28]$ & $1.77(0.33-10.40)[17]$ & 0.59 \\
\hline 2nd trimester & $2.53(0.58-22.20)[40]$ & $2.44(0.42-18.50)[29]$ & 0.63 \\
\hline 3rd trimester & $5.90(0.37-22.70)[58]$ & $4.22(0.45-19.80)[40]$ & 0.17 \\
\hline \multicolumn{4}{|l|}{ Serum/plasma creatinine $(\mu \mathrm{mol} / \mathrm{l})$} \\
\hline Prepregnancy & $82(60-122)[21]$ & $68(38-485)[24]$ & 0.08 \\
\hline 1st trimester & $70(57-144)[39]$ & $67(44-430)[31]$ & 0.10 \\
\hline 2nd trimester & $75(52-157)[28]$ & $73(44-338)[27]$ & 0.61 \\
\hline 3rd trimester & $77(59-291)[52]$ & $81(43-240)[28]$ & 0.81 \\
\hline \multicolumn{4}{|l|}{ Creatinine clearance $\left(\mathrm{ml} \mathrm{s}^{-1}[1.73 \mathrm{~m}]^{-3}\right)$} \\
\hline Prepregnancy & $1.12(0.72-2.23)[10]$ & $1.74(0.21-3.69)[8]$ & 0.27 \\
\hline 1st trimester & $1.42(0.54-2.18)[20]$ & $1.69(0.88-3.26)[12]$ & 0.50 \\
\hline 2nd trimester & $1.38(0.48-2.61)[23]$ & $1.48(0.67-2.83)[20]$ & 0.23 \\
\hline 3rd trimester & $1.31(0.25-2.20)[36]$ & $1.67(0.41-2.56)[21]$ & 0.45 \\
\hline
\end{tabular}


Renal function Total protein excretion in urine, serum or plasma creatinine and creatinine clearance were similar in the two time periods (Table 2). Systolic and diastolic BP levels in the first, second and third trimesters of pregnancy correlated with the total protein excretion in urine in each respective trimester $(r=0.54, p<0.001$ and $r=0.50, p<0.001 ; r=0.46$, $p<0.001$ and $r=0.48, p<0.001 ; r=0.50, p<0.001$ and $r=0.52$, $p<0.001$, respectively). In the third trimester, systolic and diastolic BP values also correlated positively with serum or plasma creatinine $(r=0.39, p<0.001$ and $r=0.43, p<0.001)$ and negatively with creatinine clearance $(r=-0.33, p=0.012$ and $r=-0.40, p=0.002$ ). One patient had dialysis treatment during pregnancy in 2010.

Perinatal outcome Perinatal outcomes in the two study periods are compared in Table 3 . The perinatal mortality rate was 3.4\% (5/147) during 1988-2011. One newborn infant died in 1989 due to fetal asphyxia and multiple liver and kidney malformations. Two neonatal deaths in 1991 and 1993 were due to respiratory distress syndrome after preterm CS deliveries. One stillbirth occurred in 2008 because of placental abruption and another in 2010 due to intrauterine chronic hypoxia. Major malformations were diagnosed in $9.5 \%$ $(14 / 147)$ of infants of diabetic nephropathy patients during 1988-2011.

The median (range) gestational age was 253 days (186275 ) in the total cohort. The percentages of deliveries before 32 and 37 gestational weeks remained high (Table 3). Two (3.1\%) patients in 1988-1999 and one (2.3\%) in 2000-2011 delivered before 28 gestational weeks. The total protein excretion in urine in the second and third trimesters correlated negatively with gestational age at birth $(r=-0.41, p=<0.001$ and $r=-0.38, p<0.001$, respectively). In parturients with first trimester total protein excretion $<1 \mathrm{~g} / 24 \mathrm{~h}$ or dipstick $1+$, deliveries before 37 gestational weeks were less frequent than in parturients with total protein excretion $\geq 1 \mathrm{~g} / 24 \mathrm{~h}$ or dipstick $2+$ or $3+(63.8 \%$ vs $85.0 \%$, respectively, $p=0.02)$. In logistic regression analysis, first trimester $\mathrm{BP}>130 / 80 \mathrm{mmHg}$ and the last $\mathrm{HbA}_{1 \mathrm{c}}$ before delivery were associated with preterm birth before 37 gestational weeks (Table 4).

The mean (SD) relative birthweight of infants was 0.38 (1.8) SD units in the total cohort. No statistically significant changes were observed in the mean relative birthweight or the frequencies of SGA or macrosomic infants (Table 3 ). Systolic and diastolic BP levels in the first $(r=-0.35, p<0.001$ and $r=$ $-0.27, p=0.006$, respectively), second ( $r=-0.41, p<0.001$ and $r=-0.40, p<0.001$, respectively) and third $(r=-0.32$, $p=0.001$ and $r=-0.24, p=0.01$, respectively) trimesters, blood creatinine in the third trimester $(r=-0.31, p=0.005)$ and creatinine clearance in the second and third trimesters ( $r=0.34, p=0.02$ and $r=0.43, p=0.001$, respectively) correlated with relative birthweight. In parturients with first trimester total protein excretion $<1 \mathrm{~g} / 24 \mathrm{~h}$ or dipstick $1+$, SGA infants were less frequent than in parturients with total protein excretion $\geq 1 \mathrm{~g} / 24 \mathrm{~h}$ or dipstick $2+$ or $3+(1.7 \%$ vs $17.5 \%$, respectively, $p=0.007)$. In logistic regression analysis, fetal macrosomia was predicted by maternal prepregnancy BMI (Table 4). Second trimester total protein excretion $\geq 3 \mathrm{~g} / 24 \mathrm{~h}$ and lower maternal age were associated with the delivery of an SGA infant (Table 4).

The frequencies of newborn infants with 1 min Apgar scores $<7$, umbilical artery $\mathrm{pH}<7.15$ or $<7.05$ or neonatal hypoglycaemia did not change (Table 3). A 5 min Apgar score $<7$ was given to three infants $(4.6 \%)$ in $1988-1999$ and four infants $(9.3 \%)$ in 2000-2011. In logistic regression analysis, second trimester total protein excretion $\geq 3 \mathrm{~g} / 24 \mathrm{~h}$ was associated with 1 min Apgar score $<7$ and the last $\mathrm{HbA}_{1 \mathrm{c}}$ level before delivery with umbilical artery $\mathrm{pH}<7.15$ (Table 4).
Table 3 Comparison of perinatal outcomes of 108 diabetic nephropathy patients with a singleton delivery at $\mathrm{HUCH}$ during 1988-1999 and 2000-2011

Data are means (SD), medians (range) or frequencies (\%)

The number of subjects is presented in square brackets, if different

${ }^{a}$ Only live births were included

\begin{tabular}{|c|c|c|c|}
\hline Perinatal outcome & $1988-1999(n=65)$ & $2000-2011(n=43)$ & $p$ value \\
\hline Perinatal death & $3(4.6)$ & $2(4.7)$ & 1.00 \\
\hline Gestational age (days) & $254(186-275)$ & $246(192-273)$ & 0.17 \\
\hline Delivery $<32$ weeks of gestation & $9(13.8)$ & $9(20.9)$ & 0.33 \\
\hline Delivery $<37$ weeks of gestation & $46(70.8)$ & $33(76.7)$ & 0.49 \\
\hline Birthweight (g) & $2978(971)$ & $2694(1029)$ & 0.15 \\
\hline Relative birthweight (SD units) & $0.5(1.8)$ & $0.3(1.8)$ & 0.55 \\
\hline Birthweight $>2.0$ SD units ( $>97.7$ th percentile) & $14(21.5)$ & $7(16.3)$ & 0.50 \\
\hline Birthweight $<-2.0 \mathrm{SD}$ units $(<2.3$ th percentile $)$ & $5(7.7)$ & $4(9.3)$ & 1.00 \\
\hline Birthweight $>90$ th percentile ( $>1.28$ SD units) & $23(35.4)$ & $12(27.9)$ & 0.42 \\
\hline Birthweight $<10$ th percentile $(<-1.28$ SD units) & $10(15.4)$ & $10(23.3)$ & 0.30 \\
\hline Apgar score at $1 \mathrm{~min}<7$ & $10(15.4)$ & $9(22.0)$ & 0.39 \\
\hline Umbilical artery $\mathrm{pH}<7.05^{\mathrm{a}}$ & $0(0)[64]$ & $1(2.6)[38]$ & 0.37 \\
\hline Umbilical artery $\mathrm{pH}<7.15^{\mathrm{a}}$ & $3(4.7)[64]$ & $5(10.5)[38]$ & 0.42 \\
\hline NICU admission ${ }^{\mathrm{a}}$ & $17(26.2)$ & $20(48.8)[41]$ & 0.02 \\
\hline Neonatal hypoglycaemia $^{a}$ & $39(60.0)$ & $22(53.7)[41]$ & 0.52 \\
\hline
\end{tabular}


Table 4 Maternal factors predicting adverse perinatal outcomes in 108 diabetic nephropathy patients with a singleton delivery at HUCH during 1988 2011

\begin{tabular}{|c|c|c|c|}
\hline Perinatal outcome & Maternal variable & Non-adjusted OR (95\% CI) & Adjusted OR $(95 \% \mathrm{CI})^{\mathrm{a}}$ \\
\hline \multirow[t]{2}{*}{ Delivery before 37 weeks } & First trimester $\mathrm{BP}>130 / 80 \mathrm{mmHg}^{\mathrm{b}}$ & $3.23(1.30,8.03)$ & $3.62(1.24,10.56)$ \\
\hline & Last $\mathrm{HbA}_{1 \mathrm{c}}$ before delivery $(\%)^{\mathrm{b}, \mathrm{c}}$ & $2.32(1.41,3.82)$ & $2.26(1.28,3.98)$ \\
\hline Apgar score at $1 \mathrm{~min}<7$ & Second trimester proteinuria $\geq 3 \mathrm{~g} / 24 \mathrm{~h}$ & $5.28(1.46,19.14)$ & $4.93(1.35,18.01)$ \\
\hline Umbilical artery $\mathrm{pH}<7.15^{\mathrm{d}}$ & Last $\mathrm{HbA}_{1 \mathrm{c}}$ before delivery $(\%)^{\mathrm{c}}$ & $2.62(1.17,5.83)$ & $2.39(1.05,5.42)$ \\
\hline Macrosomia ( $>2.0$ SD units) & BMI $\left(\mathrm{kg} / \mathrm{m}^{2}\right)$ & $1.22(1.04,1.42)$ & $1.24(1.05,1.45)$ \\
\hline \multirow[t]{2}{*}{ Small-for-date $(<-2.0 \mathrm{SD}$ units $)$} & Second trimester proteinuria $\geq 3 \mathrm{~g} / 24 \mathrm{~h}$ & $14.00(1.62,121.37)$ & $19.52(1.91,199.65)$ \\
\hline & Maternal age (year) ${ }^{\mathrm{c}}$ & $0.80(0.67,0.96)$ & $0.76(0.60,0.96)$ \\
\hline \multirow[t]{2}{*}{ NICU admission ${ }^{\mathrm{d}}$} & Second trimester proteinuria $\geq 3 \mathrm{~g} / 24 \mathrm{~h}^{\mathrm{e}}$ & $6.40(2.20,18.65)$ & $6.10(2.07,17.96)$ \\
\hline & First trimester $\mathrm{BP}>130 / 80 \mathrm{mmHg}^{\mathrm{e}}$ & $3.76(1.44,9.84)$ & $3.18(1.19,8.53)$ \\
\hline
\end{tabular}

${ }^{\mathrm{a}}$ Independent variables tested in the multiple logistic regression analyses were maternal age, prepregnancy BMI, first trimester BP $>130 / 80 \mathrm{mmHg}$, second trimester proteinuria $\geq 3 \mathrm{~g} / 24 \mathrm{~h}$, and last $\mathrm{HbA}_{1 \mathrm{c}}$ before delivery; only variables with $p<0.2$ in the univariate analyses were entered into the multiple models, so that 2-3 variables were used in each multiple model

${ }^{\mathrm{b}}$ Due to the correlation between first trimester $\mathrm{BP}>130 / 80 \mathrm{mmHg}$ and second trimester proteinuria $\geq 3 \mathrm{~g} / 24 \mathrm{~h}$, the latter was not included in the multiple model regarding delivery before 37 weeks

${ }^{\mathrm{c}}$ For last $\mathrm{HbA}_{1 \mathrm{c}}$ before delivery and maternal age, ORs are presented per increment

${ }^{\mathrm{d}}$ Only live births were included

${ }^{\mathrm{e}}$ Due to the correlation between first trimester BP $>130 / 80 \mathrm{mmHg}$ and second trimester proteinuria $\geq 3 \mathrm{~g} / 24 \mathrm{~h}$, the associations of these variables with NICU admission were adjusted for BMI only

The percentage of infants admitted to the NICU increased from 26.2 to $48.8 \%$ ( $p=0.02$; Table 3 ). Respiratory distress syndrome was diagnosed in 11 infants (64.7\%) in 1988-1999 and in seven infants $(35.0 \%)$ in $2000-2011(p=0.07)$. The delivery modes, preterm birth rates before 32 or 37 gestational weeks, macrosomia and SGA rates, frequencies of umbilical artery $\mathrm{pH}<7.05$ and $<7.15$, and hypoglycaemia and major malformation rates of the newborn infants admitted to the NICU did not differ between the two time periods. In logistic regression analysis, second trimester proteinuria $\geq 3 \mathrm{~g} / 24 \mathrm{~h}$ and first trimester $\mathrm{BP}>130 / 80 \mathrm{mmHg}$ were associated with NICU admission (Table 4).

\section{Discussion}

This study shows that prepregnancy and early pregnancy glycaemic control remained suboptimal and BP levels high despite increased use of antihypertensive medications in patients with diabetic nephropathy during 1988-2011. Preeclampsia, preterm delivery and CS rates were high throughout the study period and NICU admissions increased.

To the authors' knowledge, our study is the largest report to date concerning pregnancies and deliveries in women with diabetic nephropathy. The study cohort is population-based, which improves the generalisability of the results. The study period of 24 years permitted the analysis of temporal changes. Weaknesses of the study include the retrospective design, due to which we do not have quantitative proteinuria measurements and markers of renal function systematically from all patients for the prepregnancy period and all trimesters of pregnancy. Considering the criteria of diabetic nephropathy used, and the comparably high prevalence of diabetic nephropathy in both time periods, it is possible that we have included a few patients with microalbuminuria instead of overt nephropathy. However, these two groups of patients with diabetic kidney involvement share similar perinatal risks $[22,23]$.

The prevalence of diabetic nephropathy was lower in the second study period and the median diabetes duration increased, probably reflecting the delayed cumulative incidence of persistent proteinuria observed in type 1 diabetes patients recently [24]. Despite the improving prognosis of diabetic nephropathy [15], premature deaths among our patients were still common. The obesity epidemic has not affected women with diabetic nephropathy, whose median BMI has remained in the normal range. This is in contrast to our previous observations in other type 1 diabetes patients [25] and the Finnish background population, in which every third parturient is currently overweight and $13 \%$ are obese [26]. The frequency of smoking during pregnancy was higher than the $15-17 \%$ recorded in 1987-2010 for all Finnish parturients [27], but similar to the figures reported by Damm et al [4]. There is a need to intensify the antismoking counselling given to reproductive-age women with diabetic nephropathy, as smoking may promote the development of diabetic renal disease [28]. 
The International Diabetes Federation recommends a prepregnancy $\mathrm{HbA}_{1 \mathrm{c}}$ target below $7.0 \%(53 \mathrm{mmol} / \mathrm{mol})$ [29]. The median prepregnancy and early pregnancy $\mathrm{HbA}_{1 \mathrm{c}}$ levels in our study exceed this both in 1988-1999 and in 2000-2011. The early pregnancy glycaemic control in our study population is similar to that reported by Carr et al [16] and Ekbom et al [22], but worse than reported by two recent small Danish studies $[4,13]$. Since many of our patients did not attend prepregnancy care, the actual median prepregnancy $\mathrm{HbA}_{1 \mathrm{c}}$ level might be even higher. On the other hand, even though almost $80 \%$ of patients in $2000-2011$ had their $\mathrm{HbA}_{1 \mathrm{c}}$ controlled within 12 months before pregnancy, early pregnancy glycaemic control did not improve. Poor glycaemic control increases the risk of congenital malformations [30, 31], preterm delivery [32] and pre-eclampsia [33], all of which were common in our study. The rate of fetal malformations was close to the levels reported 30 years ago $[5,8]$. Since the physiological decrease in $\mathrm{HbA}_{1 \mathrm{c}}$ during pregnancy is minimal [34], the marked decrease of early pregnancy $\mathrm{HbA}_{1 \mathrm{c}}$ levels by mid-pregnancy demonstrates that improvement in glycaemic control is possible in patients with diabetic nephropathy. Comparable observations have been made by others $[4,11]$. However, this improvement should ideally take place before pregnancy, as intensive treatment is known to prevent the development or slow the progression of diabetic long-term complications and to improve pregnancy outcomes [35-37].

BP levels increased continuously towards the end of pregnancy in both time periods, despite the increased use of antihypertensive medications during pregnancy in the latter time period. Most patients exceeded the upper BP threshold of $130 / 80 \mathrm{mmHg}$ recommended by the ADA [17]. Suboptimal BP control in diabetic nephropathy patients with and without antihypertensive therapy was also found by Carr et al [16]. Even in the latter study period, antihypertensive therapy was discontinued in early pregnancy or not initiated until late in pregnancy in many cases. No clinical guidelines regarding the initiation or treatment targets of antihypertensive medication in pregnant type 1 diabetes patients with or without vascular complications exist at HUCH. The Finnish Current Care Guidelines recommend that in non-pregnant patients with diabetic nephropathy, BP should be controlled to levels $\leq 130 / 80 \mathrm{mmHg}$ [38]. The observed correlations between BP levels and markers of renal function during pregnancy are in line with previous reports $[5,8,16]$. In spite of the increased prepregnancy use of RAS inhibitors, no improvement was seen in the levels of proteinuria or the markers of renal function before pregnancy.

The exact diagnosis of pre-eclampsia in nephropathy patients with pre-existing proteinuria and hypertension is challenging. Various pre-eclampsia criteria have been used previously [7, 9, 13, 39]. A large proportion of our patients experienced further increase in hypertensive BP levels with concurrent development of massive proteinuria in the second half of pregnancy, commonly leading to preterm delivery. For this reason, we chose a strict proteinuria criterion of $\geq 5 \mathrm{~g} / 24 \mathrm{~h}$, which has also been used to define severe pre-eclampsia in patients without nephropathy [19]. Regardless of the criteria used, it may be impossible to distinguish pre-eclampsia from worsening of diabetic nephropathy based on BP and proteinuria measurements [5]. Even using our strict criteria, the preeclampsia incidence was high, which is in accordance with previous reports $[6,8-10,12,13,22]$.

The decrease in the elective CS rate among women with diabetic nephropathy is in line with our observations concerning delivery mode trends in all type 1 diabetes patients during 1989-2008 [25]. Changes in the management of type 1 diabetes pregnancies in HUCH are likely to explain these trends as until year 2000 the delivery mode of choice was CS for all patients with diabetic nephropathy. Taking into account the poor success rate of vaginal deliveries in this patient group, and the maternal and fetal risks related to emergency CS deliveries, our data suggests that elective CS might be preferred for patients with diabetic nephropathy. High CS rates (70-91\%) have been recorded also in other centres among patients with diabetic nephropathy $[4-11,14]$.

The preterm birth rate was similar $[4,5,7,12-14]$ or somewhat higher $[6,8-11]$ than in previous studies. Most of the preterm births are explained by the high rate of preeclampsia, which typically necessitates preterm delivery. Danish observational studies have reported reduction in preeclampsia and preterm delivery in type 1 diabetes patients with microalbuminuria or nephropathy after starting intensive antihypertensive treatment with $\mathrm{BP} \geq 135 / 85 \mathrm{mmHg}$ and/or urinary albumin excretion $\geq 300 \mathrm{mg} / 24 \mathrm{~h}[4,13]$. Using these treatment thresholds, BP remained stable and only $2.4 \%$ (1/41) of type 1 and 2 diabetes patients with kidney involvement developed nephrotic range proteinuria during pregnancy [4]. Considering the high frequency of hypertension and severe proteinuria in our nephropathy patients, and their associations with preterm delivery, it is possible that intensified control of BP levels starting from early pregnancy could improve outcomes $[7,16,40]$. Aggressive treatment with up to four antihypertensive drugs may be required to reach target levels, due to long-term haemodynamic alterations, such as increased peripheral vasoconstriction [13, 16, 41]. Baseline assessments of proteinuria and kidney function should be performed before or in early pregnancy in parturients with diabetes to identify those with need for strict antihypertensive control. In addition to aiming at tight glycaemic [33] and BP control [40], low-dose aspirin treatment during pregnancy has been recommended in women with pre-gestational diabetes to reduce the incidence of pre-eclampsia and associated adverse maternal and neonatal outcomes [42, 43].

Perinatal mortality in the present study was lower than the $6-11 \%$ reported in the 1980 s and 1990 s $[5,8,10]$ but no other improvements in perinatal outcomes are apparent. Diabetic 
vasculopathies reduce fetal growth, possibly due to associated placental vascular insufficiency [44], partly counteracting the growth-promoting effects of diabetes. Accordingly, in keeping with previous reports $[5,8]$, the markers of renal function during the second and third trimesters correlated with relative birthweight. Nevertheless, it should be noted that a significant proportion of pregnancies of diabetic nephropathy patients may also be complicated by fetal macrosomia, as shown by our data. However, the macrosomia rates were lower and the SGA rates higher than recently observed in type 1 diabetes patients $[2,25]$. The relatively high proportion of infants with 1 min Apgar score $<7$ may be related to the high preterm birth rate. Preterm births and emergency CSs due to pre-eclampsia may explain the association of second trimester proteinuria $>3 \mathrm{~g} / 24 \mathrm{~h}$ with $1 \mathrm{~min}$ Apgar scores $<7$. Poor maternal glycaemic control in late pregnancy predisposes to fetal chronic hypoxia [45], which is in agreement with our observation of the association between the last $\mathrm{HbA}_{1 \mathrm{c}}$ level before delivery and umbilical artery $\mathrm{pH}<7.15$.

Advancements in the care of preterm infants during the last two decades may have contributed to the prevention of early neonatal deaths in the latter study period. Surfactant treatment was started at HUCH in 1991 and glucocorticoid administration to the mother in threatened preterm delivery in 1992. Nasal continuous positive airway pressure treatment became available in the neonatal monitoring unit of the labour ward in 2002. Despite these improvements, and the unchanged rates of fetal macrosomia, SGA infants, neonatal hypoglycaemia and pre-eclampsia, the NICU admission rate increased. This could be due to the high frequency of births before 32 and 37 weeks of gestation in the latter study period. The high emergency CS rate, associated with an elevated likelihood of fetal distress, may also have contributed to the NICU admission rate during 2000-2011. Preterm CSs due to preeclampsia in patients with chronic hypertension and significant proteinuria may have led to the association of first trimester hypertension and second trimester proteinuria $\geq 3 \mathrm{~g} / 24 \mathrm{~h}$ with NICU admission, although this could also be a chance finding.

In conclusion, pre-eclampsia and preterm delivery rates have remained high and BP levels as well as early pregnancy glycaemic control suboptimal in parturients with diabetic nephropathy. The rapid decrease of high early pregnancy $\mathrm{HbA}_{1 \mathrm{c}}$ levels by mid-pregnancy suggests that improvement of glycaemic control could be possible in diabetic nephropathy patients already before pregnancy with active follow-up and treatment. The high frequency of hypertension throughout pregnancy despite the increased use of antihypertensive medications calls for more attention on controlling BP in diabetic nephropathy. Prospective studies are needed to evaluate the impact of intensified antihypertensive treatment and low-dose aspirin during pregnancy on pregnancy outcomes in women with diabetic nephropathy.
Acknowledgements The authors thank H. Puttonen (Department of Obstetrics and Gynecology, HUCH) for her invaluable assistance in retrieving information from patient records.

Funding The National Graduate School of Clinical Investigation, Helsinki University Research Foundation, Viipuri Tuberculosis Foundation and the Maud Kuistila Memorial Foundation have supported this work as part of MK's $\mathrm{PhD}$ studies.

Duality of interest The authors declare that there is no duality of interest associated with this manuscript.

Contribution statement MK participated in the study design, acquisition of data and data entry, prepared the database and carried out the statistical analyses. In addition, she prepared the first draft, and edited and finalised the manuscript. HL, VH, MT and MN participated in the interpretation of data, contributed to discussions and critically reviewed drafts of the manuscript. VH provided expert advice in biostatistics. KT initiated and planned the study, participated in the acquisition of data and drafted and critically reviewed, commented on and edited various versions of the manuscript. MK and KT are the guarantors of this work. All authors read and approved the final version of the manuscript.

\section{References}

1. Casson IF (2006) Pregnancy in women with diabetes - after the CEMACH report, what now? Diabet Med 23:481-484

2. Persson M, Norman M, Hanson U (2009) Obstetric and perinatal outcomes in type 1 diabetic pregnancies: a large, population-based study. Diabetes Care 32:2005-2009

3. Landon MB (2007) Diabetic nephropathy and pregnancy. Clin Obstet Gynecol 50:998-1006

4. Damm JA, Asbjörnsdóttir B, Callesen NF et al (2001) Diabetic nephropathy and microalbuminuria in pregnant women with type 1 and type 2 diabetes: prevalence, antihypertensive strategy, and pregnancy outcome. Diabetes Care 36:3489-3494

5. Kitzmiller JL, Brown ER, Phillippe M (1981) Diabetic nephropathy and perinatal outcome. Am J Obstet Gynecol 141:744-751

6. Grenfell A, Brudenell JM, Doddridge MC, Watkins PJ (1986) Pregnancy in diabetic women who have proteinuria. QJM 59:379386

7. Kimmerle R, Zass RP, Cupisti S et al (1995) Pregnancies in women with diabetic nephropathy: long-term outcome for mother and child. Diabetologia 38:227-235

8. Reece EA, Coustan DR, Hayslett JP et al (1988) Diabetic nephropathy: pregnancy performance and fetomaternal outcome. Am J Obstet Gynecol 159:56-66

9. Gordon M, Landon MB, Samuels P, Hissrich S, Gabbe SG (1996) Perinatal outcome and long-term follow-up associated with modern management of diabetic nephropathy. Obstet Gynecol 87:401-409

10. Miodovnik M, Rosenn BM, Khoury JC, Grigsby JL, Siddiqi TA (1996) Does pregnancy increase the risk for development and progression of diabetic nephropathy? Am J Obstet Gynecol 174:1180 1189

11. Dunne FP, Chowdhury TA, Hartland A et al (1999) Pregnancy outcome in women with insulin-dependent diabetes mellitus complicated by nephropathy. QJM 92:451-454

12. Biesenbach G, Grafinger P, Zazgornik J, Stöger H (2000) Perinatal complications and three-year follow up of infants of diabetic mothers with diabetic nephropathy stage IV. Ren Fail 22:573-580

13. Nielsen LR, Damm P, Mathiesen ER (2009) Improved pregnancy outcome in type 1 diabetic women with microalbuminuria or diabetic 
nephropathy: effect of intensified antihypertensive therapy? Diabetes Care 32:38-44

14. Piccoli GB, Tavassoli E, Melluzza C et al (2013) Severe diabetic nephropathy in type 1 diabetes and pregnancy - a case series. Rev Diabet Stud 10:68-78

15. Andrésdóttir G, Carstensen B, Parving HH, Hovind P, Hansen TW, Rossing P (2014) Improved prognosis of diabetic nephropathy in type 1 diabetes. Kidney Int. doi:10.1038/ki.2014.206

16. Carr DB, Koontz GL, Gardella C et al (2006) Diabetic nephropathy in pregnancy: suboptimal hypertensive control associated with preterm delivery. Am J Hypertens 19:513-519

17. Kitzmiller JL, Block JM, Brown FM et al (2008) Managing preexisting diabetes for pregnancy: summary of evidence and consensus recommendations for care. Diabetes Care 31:1060-1079

18. Lindheimer MD, Kanter D (2010) Interpreting abnormal proteinuria in pregnancy. The need for a more physiologic approach. Obstet Gynecol 115:365-375

19. ACOG Committee on Obstetric Practice (2002) ACOG practice bulletin. Diagnosis and management of preeclampsia and eclampsia. Obstet Gynecol 99:159-167

20. Roberts JM, Pearson G, Cutler J, Lindheimer M (2003) Summary of the NHLBI Working Group on research on hypertension during pregnancy. Hypertension 41:437-445

21. Pihkala J, Hakala T, Voutilainen P, Raivio K (1989) Characteristics of recent fetal growth curves in Finland. Duodecim 105:1540-1546

22. Ekbom P, Damm P, Feldt-Rasmussen B, Feldt-Rasmussen U, Mølvig J, Mathiesen ER (2001) Pregnancy outcome in type 1 diabetic women with microalbuminuria. Diabetes Care 24:1739-1744

23. Combs CA, Rosenn B, Kitzmiller JL, Khoury JC, Wheeler BC, Miodovnik M (1993) Early-pregnancy proteinuria in diabetes related to preeclampsia. Obstet Gynecol 82:802-807

24. Marshall SM (2012) Diabetic nephropathy in type 1 diabetes: has the outlook improved since the 1980s? Diabetologia 55:2301-2306

25. Klemetti M, Nuutila M, Tikkanen M, Kari MA, Hiilesmaa V, Teramo K (2012) Trends in maternal BMI, glycaemic control and perinatal outcome among type 1 diabetic pregnant women in 1989-2008. Diabetologia 55:2327-2334

26. National Institute for Health and Welfare (2013) Perinatal statistics: parturients, deliveries and newborns 2012. Statistical report 24/2013, 27.9.2013. Official Statistics of Finland, Helsinki

27. National Institute for Health and Welfare (2012) Tobacco Statistics 2011. Statistical report 23/2012, 24.10.2012. Official Statistics of Finland, Helsinki

28. Scott LJ, Warram JH, Hanna LS, Laffel LM, Ryan L, Krolewski AS (2001) A nonlinear effect of hyperglycemia and current cigarette smoking are major determinants of the onset of microalbuminuria in type 1 diabetes. Diabetes 50:2842-2849

29. International Diabetes Federation (2008). Global guidelines on pregnancy and diabetes. Available from www.idf.org/webdata/docs/ Pregnancy_EN_RTP.pdf. Accessed 23 July 2014

30. Bell R, Glinianaia SV, Tennant PWG, Bilious RW, Rankin J (2012) Peri-conception hyperglycaemia and nephropathy are associated with risk of congenital anomaly in women with pre-existing diabetes: a population-based cohort study. Diabetologia 55:936947
31. Suhonen L, Hiilesmaa V, Teramo K (2000) Glycaemic control during early pregnancy and fetal malformations in women with type 1 diabetes mellitus. Diabetologia 43:79-82

32. Lepercq J, Coste J, Theau A, Dubois-Laforgue D, Timsit J (2004) Factors associated with preterm delivery in women with type 1 diabetes: a cohort study. Diabetes Care 27:2824-2828

33. Hiilesmaa V, Suhonen L, Teramo K (2000) Glycaemic control is associated with pre-eclampsia but not with pregnancy-induced hypertension in women with type 1 diabetes mellitus. Diabetologia 43: 1534-1539

34. Ylinen K, Hekali R, Teramo K (1981) Haemoglobin Alc during pregnancy of insulin-dependent diabetics and healthy controls. J Obstet Gynaecol 1:223-228

35. The Diabetes Control and Complications Trial Research Group (1993) The effect of intensive treatment of diabetes on the development and progression of long-term complications in insulindependent diabetes mellitus. N Engl J Med 329:977-986

36. Writing Team for the Diabetes Control and Complications Trial/ Epidemiology of Diabetes Interventions and Complications Research Group (2003) Sustained effect of intensive treatment of type 1 diabetes mellitus on development and progression of diabetic nephropathy: the Epidemiology of Diabetes Interventions and Complications (EDIC) study. JAMA 290:21592167

37. The Diabetes Control and Complications Trial Research Group (1996) Pregnancy outcomes in the Diabetes Control and Complications Trial. Am J Obstet Gynecol 174:1343-1353

38. Working group set up by the Finnish Medical Society Duodecim and the Finnish Society of Nephrology (2007) Diabetic nephropathy. Current Care Guidelines. Available from www.kaypahoito.fi. Accessed 6 Oct 2014

39. Sibai BM, Caritis S, Hauth J et al (2000) Risks of preeclampsia and adverse neonatal outcomes among women with pregestational diabetes mellitus. Am J Obstet Gynecol 182:364-369

40. Mathiesen ER, Ringholm L, Feldt-Rasmussen B, Clausen P, Damm P (2000) Obstetric nephrology: pregnancy in women with diabetic nephropathy - the role of antihypertensive treatment. Clin J Am Soc Nephrol 7:2081-2088

41. van Buren PN, Toto R (2011) Hypertension in diabetic nephropathy: epidemiology, mechanisms, and management. Adv Chron Kidney Dis 18:28-41

42. LeFevre ML, on behalf of the U.S. Preventive Services Task Force (2014) Low-dose aspirin use for the prevention of morbidity and mortality from preeclampsia: U.S. Preventive Services Task Force recommendation statement. Ann Intern Med 131:819-826

43. National Institute for Health and Clinical Excellence (2010) Hypertension in pregnancy: the management of hypertensive disorders during pregnancy. NICE clinical guideline 107. Available from www.guidance.nice.org.uk/cg107. Accessed 18 Oct 2014

44. Haeri S, Khoury J, Kovilam O, Miodovnik M (2008) The association of intrauterine growth abnormalities in women with type 1 diabetes mellitus complicated by vasculopathy. Am J Obstet Gynecol 199: 278.e1-5

45. Teramo K, Kari MA, Eronen M, Markkanen H, Hiilesmaa V (2004) High amniotic fluid erythropoietin levels are associated with an increased frequency of fetal and neonatal morbidity in type 1 diabetic pregnancies. Diabetologia 47:1695-1703 